\title{
Generic revision of Notodasus Fauchald, 1972 (Polychaeta: Capitellidae) with descriptions of four new species from the coasts of Mexico
}

\author{
MARÍA ELENA GARCÍA-GARZA ${ }^{1}$, VICTOR DANIEL HERNÁNDEZ-VALDEZ ${ }^{2}$ and \\ JESUUS ANGEL DE LEÓN-GONZÁLEZ ${ }^{1}$ \\ ${ }^{1}$ Laboratorio de Biosistemática, Facultad de Ciencias Biológicas, Universidad Autónoma de Nuevo León. AP. 5 “F”, San \\ Nicolás de los Garza, Nuevo León, México. E-mail: mgarcia97@hotmail.com \\ ${ }^{2}$ Centro Interdisciplinario de Ciencias del Mar, CICIMAR-IPN, Playa el Conchalito s/n, La Paz, Baja California Sur. \\ México.
}

\begin{abstract}
SUMMARY: The capitellid genus Notodasus Fauchald, 1972 is emended and its previously known species are redescribed Since the original descriptions of N. magnus Fauchald, 1972, N. dexterae Fauchald, 1973, and N. arenicola Hartmann-Schröder, 1992 omitted important morphological details and were either incomplete or misleading, these species are redescribed based upon examination of type materials. Four new species are described from tropical localities in Mexico: Notodasus harrisae $\mathrm{n}$. sp., N. hartmanae n. sp., N. kristiani n. sp. and N. salazari n. sp. Standardised descriptions are provided for all species including the methyl green staining pattern, the epithelial texture and the shape of hooded hooks. A key for all described species is provided.
\end{abstract}

Keywords: polychaetes, capitellids, Notodasus, new species, systematics, Mexico.

RESUMEN: Revisión del gÉNero Notodasus Fauchald, 1972 (Polychaeta: Capitellidae) Con la descripción de CuATro nueVAS ESPECIES DE LAS COSTAS DE MÉXICO. - Se enmienda el género Notodasus Fauchald, 1972 y se redescriben las especies que lo forman. Las descripciones originales de N. magnus Fauchald, 1972, N. dexterae Fauchald, 1973 y N. arenicola HartmannSchröder, 1992 o bien eran incompletas o bien incluyen errores, por lo que dichas especies se redescriben en base al material tipo. Además, se describen cuatro nuevas especies en base a especimenes recolectados en localidades tropicales de México: Notodasus harrisae n. sp., N. hartmanae n. sp., N. kristiani $\mathrm{n}$. sp. y N. salazari n. sp. Se han realizado descripciones estandarizadas para todas las especies, las cuales incluyen el patrón de tinción con verde de metilo, la textura del epitelio y la forma de los ganchos encapuchados. Finalmente, se incluye una clave de todas las especies descritas del género.

Palabras clave: poliquetos, capitélidos, Notodasus, nuevas especies, sistemática, México.

\section{INTRODUCTION}

The family Capitellidae seems very well studied due to the many publications on Capitella capitata. This species has been regarded as both a cosmopolitan species and an indicator of organic pollution (Reish, 1957), and has been used in many experiments (Méndez, 2002). In fact, little study has been devoted to the rest of the family and consequently it is among the least studied groups. For example, there has been no revision of the whole family since Hartman (1947). Despite a number of faunistic publications, there remain many problematic groups within the family. 
The genus Notodasus is one of the poorly studied groups. It was established by Fauchald (1972) to include N. magnus Fauchald, 1972, its type species, from Carmen Island (Gulf of California). The genus was erected as having 11 thoracic chaetigers with bilimbate capillary chaetae, the first chaetiger being uniramous and the first two abdominal chaetigers having only capillary chaetae. Fauchald (1973) later described $N$. dexterae from Naos Island (Pacific Panama), and Hartmann-Schröder (1992) described N. arenicola from Ascension Island (central Atlantic Ocean). These two species match the original diagnosis of Notodasus except that they both have biramous parapodia in the first chaetiger.

The study of some specimens from several localities from the Atlantic and Pacific coasts of Mexico resulted in some undescribed species belonging to Notodasus. This prompted the study of the type materials for all species and the results are presented herein as a revision, with a redefinition of the genus and descriptions of all previously known species, together with the description of four new species.

\section{MATERIAL AND METHODS}

Type material was examined from the Natural History Museum of Los Angeles County, Allan Hancock Foundation Polychaete Collection (LACM-AHF) and the Zoologisches Museum of the Universität Hamburg $(\mathrm{ZMH})$. Material of the new species and non-type specimens were collected by hand, mostly intertidally at several localities on both coasts of Mexico. Specimens were fixed in a $10 \%$ formaldehyde sea-water solution, washed with tap water to remove the fixing agent, and preserved in $80 \%$ ethanol. Holotypes and paratypes were deposited in the Colección Poliquetológica de la Universidad Autónoma de Nuevo León (UANL), and some paratypes were deposited in LACM-AHF, in the Museum National d'Histoire Naturelle, Paris (MNHN), and in the Zoologisches Museum, Universität Hamburg $(\mathrm{ZMH})$. The methyl green staining pattern (MGSP) was used to determine specific patterns of glandular areas. We submerged specimens for one or two minutes in a solution of methyl green in $70 \%$ alcohol and washed them in several alcohol changes to eliminate the excess (Warren et al. 1994). Green (2002) included a detailed discussion of morphological terminology, principally on hooded hooks; in addition to the characters used by Green, we employed the proportion and form of the main fang (triangular or subtriangular).

\section{SYSTEMATICS}

Family CAPITELlidae Grube, 1862

Genus Notodasus Fauchald, 1972, emended

Notodasus Fauchald, 1972: 246-247, Pl. 51 Fig. a-c.

Type species. Notodasus magnus Fauchald, 1972.

Diagnosis. Thorax with eleven chaetigers with bilimbate capillary chaetae. First chaetiger biramous. First two abdominal chaetigers with bilimbate capillaries on both rami, following ones with hooded hooks. Lateral organs and branchiae present.

Remarks. The genus Notodasus was erected by $N$. magnus Fauchald (1972). In the original description, Fauchald assumes that Notodasus had only a neuropodium on the first chaetiger, but our revision of the $N$. magnus holotype showed the presence of a notopodium and a neuropodium on the first chaetiger.

Notodasus differs from other capitellids by the presence of bilimbate capillaries on both rami of the first two abdominal segments. Notodasus is very close to Notomastus, both having eleven thoracic chaetigers with bilimbate capillary chaetae, but in Notomastus all abdominal parapodia possess only hooded hooks, while Notodasus has bilimbate capillary chaetae on the first two abdominal parapodia. Dodecaseta is also similar to Notodasus in that it has eleven thoracic chaetigers with bilimbate capillary, but differs in the chaetae arrangement of the first two abdominal segments. The holotype of Dodecaceta oraria was found to have capillary chaetae mixed with hooded hooks in both the notopodia and the neuropodia of the first abdominal segment, whereas the second abdominal segment had only hooded hooks on both rami. McCammon and Stull (1978) explain the possible chaetal variation in Dodecaseta oraria: "the first abdominal neuropodium may bear all capillary chaetae, all rostrate uncini, or a mixture of both." Dodecaceta eibyejacobseni, described by Green (2002) from the Andaman Sea, could be included under Notodasus due to the presence of eleven thoracic and bilimbate capillary chaetae on both rami of the first two abdominal chaetigers, but the type material was not available for a detailed revision. Notodasus differs from other genera with eleven thoracic segments as follows: Mastobranchus has the first two abdominal chaetigers with mixed hooks and capillaries; Rashgua lacks chaetae in the abdominal notopodia. Like Dasybranchus, Notodasus possess 


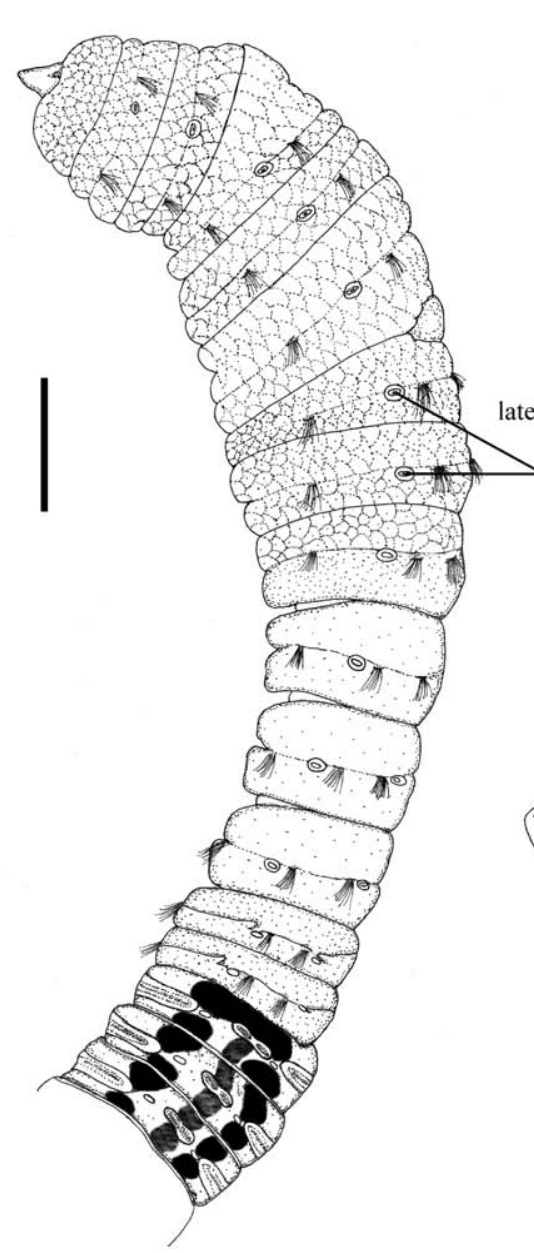

A

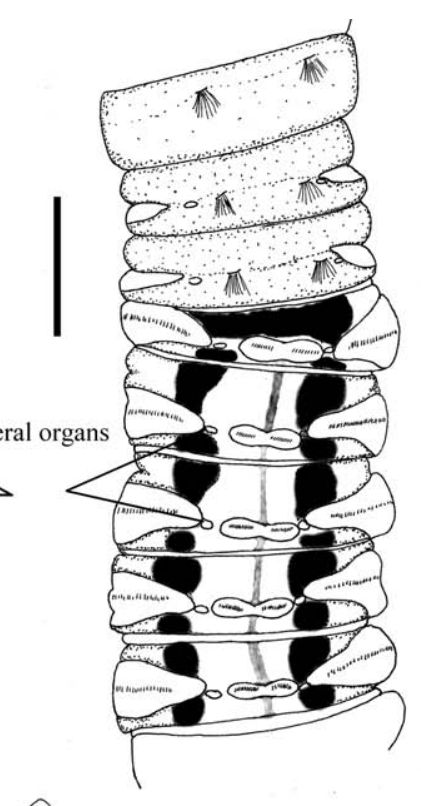

B

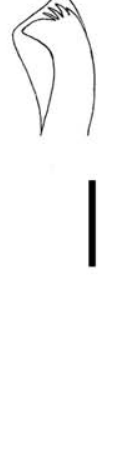

$\mathbf{E}$

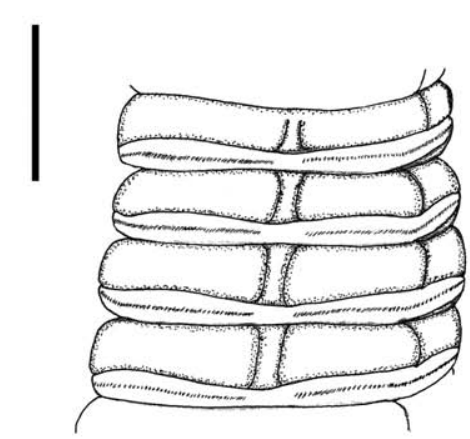

C

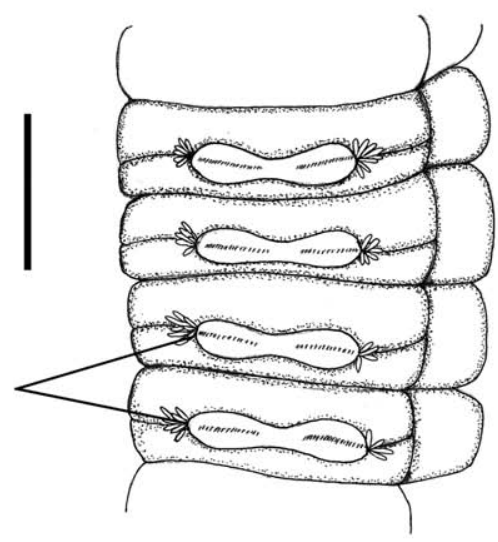

D

Fig. 1. - Notodasus arenicola A, anterior end, lateral view; B, chaetigers 11-18, dorsal view; C, chaetigers 82-85, ventral view; D, chaetigers 162-165, ventral view; E, neurohook from chaetiger 20, lateral view and detail. Shading on A-B indicates methyl green stain. Scale bars: $\mathrm{A}-\mathrm{D}=1 \mathrm{~mm}, \mathrm{E}=15 \mu \mathrm{m}$.

thirteen chaetigers with capillaries chaetae, but in Notodasus the transition between thorax and abdomen is given by the longitude change of the two region segments, evidenced in all its species, in which the first abdominal segment corresponds to half the size of the last thoracic segments. Furthermore, a constriction between the two regions is evident; in Dasybranchus the transition between the thorax and the abdomen is given by the chaetal change, and no changes are observed changes in the segment structure.

Notodasus arenicola Hartmann-Schröder, 1992 Figs. 1A-E, 8A

Notodasus arenicola Hartmann- Schröder, 1992: 232-233, Fig. 21-25.

Material examined. Paratype (ZMH P-20661), Ascension Island, Stn. 89-931, Mars Bay, November 101989.
Redescription. The following redescription is based upon the paratype; the holotype was not available. Paratype complete but broken in two, with more than 300 segments, $270 \mathrm{~mm}$ long, and $2 \mathrm{~mm}$ wide in abdomen. Anterior fraction with 244 chaetigers and $220 \mathrm{~mm}$, posterior one with 56 chaetigers and $22 \mathrm{~mm}$. Colour in alcohol dark brown. Prostomium conical with a small palpode. Eyespots present. First nine segments including peristomium, with tessellated epithelium, subsequent segments smooth (Fig. $1 \mathrm{~A})$.

Thorax with 11 chaetigers with bilimbate capillaries in both rami. All segments biannulated. Chaetae inserted in middle part of thoracic segments. Thoracic notopodia lateral in the first segments, moving dorsally posteriorly.

Distinct lateral organs protruding, between the noto- and neuropodia throughout the body; nearer 
to the notopodia, as a small pore in the thorax and closer to the neuropodia in abdominal segments. Genital pores not seen.

Transition between thorax and abdomen marked by the abrupt reduction in the abdominal segment length. Notopodial lobes from chaetigers 13-20 short, fused medially, with a line of approximately 70 hooded hooks, separated dorsally by constriction along abdomen (Fig. 1B); notopodial lobes separate from chaetiger 20. Abdominal neuropodial lobes fused ventrally, anteriorly, with about 160 hooded hooks (Fig. 1C); posterior lobes shorter, with around 80 hooded hooks per fascicle (Fig. 1D). Notopodial and neuropodial abdominal hooded hooks similar along body, with long anterior shaft, angled node, moderate constriction, slight shoulder and short hood; posterior shaft curved, longer than anterior one, attenuated to the end. Four rows of teeth above triangular main fang, basal row with four teeth, middle basal row with three, middle apical row with three and distal row with two teeth (Fig. 1E).

Branchiae retractile, occurring ventrally on posterior abdominal segments, evident from chaetiger 162. Branchiae with tuft of around 10 digitate lobes projecting from lateral end of neuropodial lobe (Fig. 1D). Pygidium smooth. Gametes absent.

Methyl green staining pattern. The stain differs in thorax and abdomen. Peristomium and thoracic chaetigers 1-5 staining slightly, following thoracic segments and first and second abdominal segments with medium intensity. Prechaetal area of the third abdominal segment with a dark transverse line; three longitudinal bands from postchaetal area of the third abdominal segment, central band less pigmented, laterals darker interrupted by lateral organs and intersegmental ring; central band interrupted by intersegmental ring and notopodial lobes (Figs. 1A-B, 8A).

Habitat. Rock pools, between calcareous algae and rocky sand, $0.5 \mathrm{~m}$ depth.

Type locality. Ascension Island (central Atlantic Ocean).

Distribution. Panam beach and Mars Bay, Ascension Island (central Atlantic Ocean).

Remarks. In the description of $N$. arenicola, Hartmann Schröder (1992) mentioned the absence of eyespots in the holotype, but the paratype examined has eyespots partially covered by the peristomium. Also, she described lateral organs only to chaetiger 8 ; in our analyses we observed lateral organs throughout the entire body.

Notodasus dexterae Fauchald, 1973

$$
\text { Fig. 2A-D, 8B }
$$

Notodasus dexterae Fauchald, 1973: 27-28, Fig. 2b -f.

Material examined. Holotype (LACM-AHF POLY-2190) and 29 specimens paratypes, Naos Island, 8`53’ N, 79³3’W, July 1969. All specimens in a bottle, only the holotype designated.

Redescription. Holotype anterior fragment, with 29 chaetigers, $13 \mathrm{~mm}$ long and $1 \mathrm{~mm}$ wide in the abdomen. Paratypes $8-15 \mathrm{~mm}$ long by $1 \mathrm{~mm}$ wide. Colour in alcohol yellowish brown. Prostomium conical, depressed, with distal palpode. Eyespots present. Proboscis everted, globose, papillated, partially broken; coarser papillation on proximal part of proboscis. Peristomium and first five thoracic chaetigers with epithelium tessellated, following segments smooth (Fig. 2A).

Thorax with 11 chaetigers, with bilimbate capillaries in both rami. Thoracic segments biannulated, abdominals uniannulated. Chaetae inserted in middle part of thoracic segments. Notopodia lateral in the first thoracic segments, moving dorsally in subsequent segments.

Lateral organs present along the body, located between noto- and neuropodia; those on thoracic segments closer to notopodia, as small rounded pores; those on abdominal region closer to neuropodia, larger, projecting. Genital pores small, poorly visible, located between intersegmental rings of segments $8 / 9,9 / 10$ and 10/11.

Transition between thorax and abdomen marked by reduced length of the first two abdominal segments; remaining abdominal segments as long as thoracic ones (Fig. 2B). Abdomen with notopodial lobes short, fused, with a small line of 9 hooded hooks per fascicle, separated dorsally along the abdomen (Figs. 2B-C). Neuropodial lobes projected to the dorsal region, each with a line of around 150 hooded hooks per fascicle, separated ventrally. Notopodial and neuropodial abdominal hooded hooks similar along the body, with long anterior shaft, indistinct constriction, bulbous node extended to posterior end, short shoulder, hood short, inserted medially on shoulder; posterior shaft shorter than anterior one. Five rows of teeth above triangular main fang, basal row with nine teeth, middle basal row with five, middle apical row with three and distal two rows, with only one 

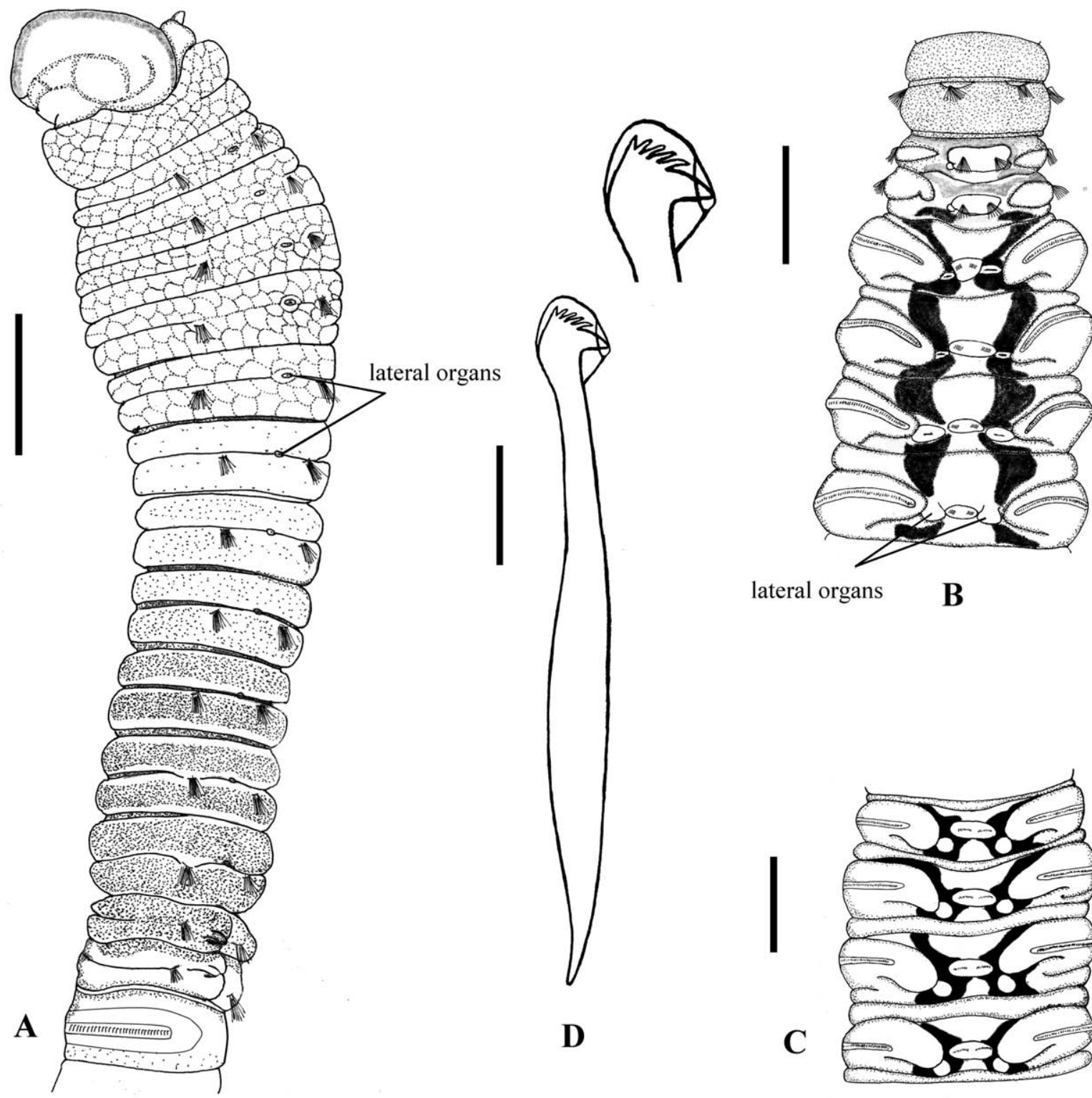

lateral organs $\quad$ B

FIG. 2. - Notodasus dexterae: A, anterior end, lateral view; B, chaetigers 11-17, dorsal view; C, chaetigers 26-29, dorsal view; D, neuropodial hook from chaetiger 28 , lateral view, and detail. Shading on A-C indicates methyl green stain. Scale bar: A-C $=0.5 \mathrm{~mm}, \mathrm{D}=10 \mu \mathrm{m}$.

tooth. Main fang subtriangular, slightly longer than wide (Fig. 2D).

Branchiae and pygidium not seen. Posterior part of body with eggs in coelom, each egg about 14.7 $\mu \mathrm{m}$ in diameter.

Methyl green staining pattern. Weakly staining from the peristomium to chaetiger 8 ; more darkly staining from thoracic chaetiger 9 to second abdominal segment. Intersegmental area stained slightly (Fig. 2 A). Postchaetal area of second abdominal chaetiger with a transverse continuous dark line. From third abdominal segment, two dorsolateral dark bands, interrupted by parapodial lobes and lateral organs (Figs. 2 B-C, 8 B).

Habitat. Intertidal sands.

Type locality. Naos Island, (Pacific coast of Panama).

Distribution. Only known from Naos Island, Panama Bay.

Remarks. Fauchald (1973) indicated that notopodia were reduced from chaetiger 15; we have found 

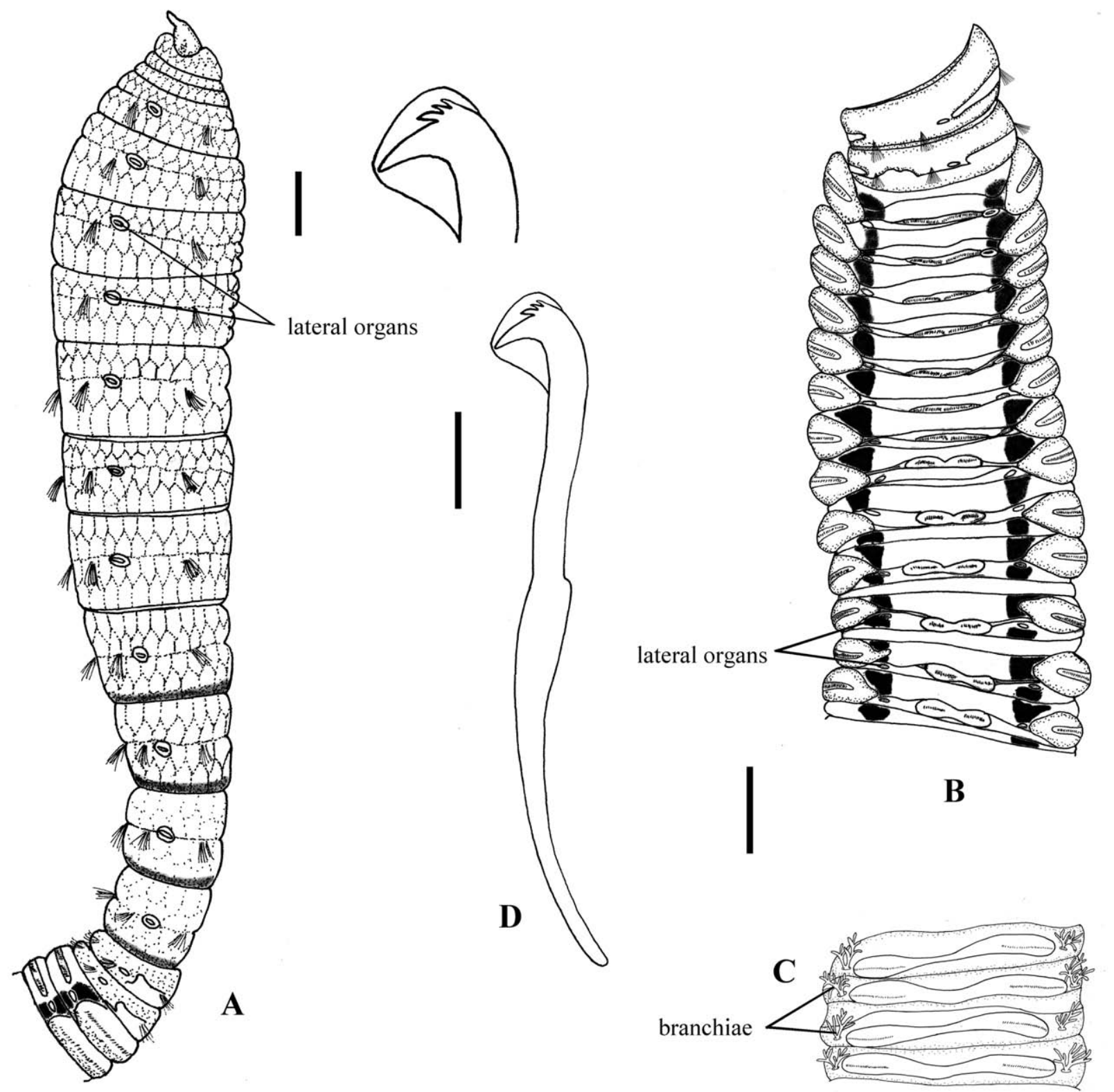

FIG. 3. - Notodasus harrisae n. sp. A, anterior end, lateral view; B, chaetigers 12-26, dorsal view; C, chaetigers 145-148, ventral view of specimen from Varadero beach; D, neuropodial hook from chaetiger 30, lateral view, and detail. Shading on A-B indicates methyl green stain, Scale bar: A-C $=1 \mathrm{~mm}, \mathrm{D}=15 \mu \mathrm{m}$.

that the notopodial lobes are present in all abdominal segments of the holotype and additional specimens; Fauchald also mentions that the hooded hooks have three teeth rows on the main fang, but in the type material we find the presence of five rows on the main fang.

\section{Notodasus harrisae n. sp.}

Fig. 3A-D, 8C

Type material. Holotype (UANL 6510), 1 Paratype (LACM-AHF), 1 Paratype (MNHN), all collected in Baja California Sur, La Paz Bay, El Tesoro beach, $24^{\circ} 15^{\prime} 16.1^{\prime \prime} \mathrm{N}, 110^{\circ} 18^{\prime} 55.4^{\prime \prime} \mathrm{W}, 1 \mathrm{~m}$ depth, August
1, 2006, coll. J.A. de León González (JALG) and M.E. García Garza. (MEGG).

Non-type material. Sinaloa, Mazatlán, Estero de Urías, (1, ICMyL EMU-420), $23^{\circ} 12^{\prime} \mathrm{N}, 106^{\circ} 23^{\prime} \mathrm{W}, 0 \mathrm{~m}$ depth, January 1979, coll. Agnes Rutgers; Baja California Sur, El Mogote beach, Stn. 89 (4, UANL 6505), $24^{\circ} 10^{\prime} 39^{\prime}$ 'N, $110^{\circ} 22^{\prime} 75^{\prime}$ 'W, $0.50 \mathrm{~m}$ depth, October 2003, coll. A. Chávez; Ensenada de La Paz, Stn. 2 (1, UANL 6506) $24^{\circ} 06^{\prime} 30.6^{\prime \prime} \mathrm{N}, 110^{\circ} 24^{\prime} 05.1^{\prime \prime} \mathrm{W}, 0.15 \mathrm{~cm}$ depth, November 27 2005; Stn. 5 (2, UANL 6507) $24^{\circ} 08^{\prime} 53.4^{\prime}{ }^{\prime} \mathrm{N}, 110^{\circ} 20^{\prime} 17.3^{\prime}{ }^{\prime} \mathrm{W}, 0$. $15 \mathrm{~cm}$ depth, June 5 2006, coll. D. Hernández-Valdez; El Requesón beach (1, UANL 6508), 26 $44^{\prime} 39.1^{\prime \prime} \mathrm{N}, 111^{\circ} 49^{\prime} 55.5^{\prime}$ ' $\mathrm{W}, 1 \mathrm{~m}$ depth, June 25 2005; El Quemadito beach (1, UANL 6509), 2645'33.1' $\mathrm{N}$, $111^{\circ} 52^{\prime} 36.5^{\prime}$ 'W, 1 m depth, June 262005 , colls. JALG and MEGG;

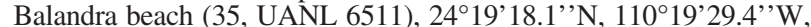
$1 \mathrm{~m}$ depth, August 1 2006, coll. JALG and MEGG. Baja California, Los Angeles Bay, Municipal beach (1, UANL 6512), 28 $57^{\prime} 10.8^{\prime \prime} \mathrm{N}$, $113^{\circ} 33^{\prime 2} 27.0^{\prime}$ 'W, 1 m depth, June 27 2005, coll. JALG and MEGG. 
Description. Holotype, anterior fragment with 99 segments, $60 \mathrm{~mm}$ long by $2 \mathrm{~mm}$ wide in abdomen. Paratypes and other specimens $59-220 \mathrm{~mm}$ long by 2-3 $\mathrm{mm}$ wide. Colour in alcohol light brown. Prostomium conical, with palpode. Eyespot present, partially covered by anterior margin of peristomium. First ten thoracic segments with epithelium longitudinally striated, thoracic chaetigers 10 and 11 slightly tessellated; abdominal segments with smooth epithelium (Fig. 3A).

Thorax with 11 chaetigers, with bilimbate capillaries in both rami. Thoracic and abdominal segments are biannulated. Notopodia lateral in the first thoracic segments, moving dorsally in subsequent segments.

Lateral organs present along the body, located between notopodia and neuropodia; those on thoracic region closer to notopodium, abdominal ones closer to neuropodial lobe. Thoracic lateral organs larger than abdominals. Genital pores not seen.

Transition between thorax and abdomen marked by abrupt shortening of abdominal segments. Notopodial lobes of abdominal chaetigers 3-9 fused dorsally, each line of hooded hooks almost fused, each with approximately 50 hooks; following segments with a middle constriction; chaetal fascicles clearly separated (Fig. 3B). Neuropodial lobes fused in abdominal chaetal fascicles with about 135 hooded hooks. Notopodia and neuropodial abdominal hooded hooks similar along the body, with long anterior shaft, angled node, distinct constriction, developed shoulder, short hood, and posterior shaft longer than anterior one. Three rows of teeth above main fang, basal row with five, middle with nine and distal one multidentate. Main fang subtriangular, longer than wide (Fig. 3D).

Branchiae emerge from a ventral pore, evident from chaetiger 60, with around 14 well-developed filaments (Fig. 3C). Pygidium not present. Posterior of body with eggs in the coelom, each egg about $68 \mu \mathrm{m}$ of diameter.

Methyl green staining pattern. Peristomium and first seven chaetigers weakly staining; first and second abdominal chaetiger slightly darker staining ventrally and laterally, subsequent twenty abdominal segments with two dark dorso-lateral longitudinal bands, separated by lateral organs, (Figs. 3B, 8C). Remaining segments with a light green continuous discrete dorsal band. Abdominal ventrum with a narrow traverse band, at the posterior margin of each neuropodial lobe.
Habitat. These specimens were collected from different substrates characterised by fine sands with high content of organic matter and shell fragments (Estero de Urías and Ensenada de La Paz), sandy beach with high energy (El Mogote), sandy beach with low energy (El Tesoro beach, Balandra beach, La Choya Beach, Los Angeles bay, Municipal beach), sandy beach with coarse sand (El Quemadito, Los Cocos beach and Santispac beach and mangrove).

Type locality. El Tesoro beach, La Paz Bay (Gulf of California).

\section{Distribution. Gulf of California.}

Etymology. The species is named in honour of Leslie Harris for her constant support and help during our visits to the Los Angeles Museum.

Remarks. Notodasus harrisae n. sp. resembles $N$. dexterae $\mathrm{n}$. sp. by having fused anterior abdominal notopodial lobes; however, those from $N$. harrisae are long and thin, while in $N$. dexterae they are short and wide. The number of hooded hooks on the notopodial lobes of both species also differs; $N$. harrisae has around 50 hooks in each fascicle, while $N$. dexterae has 9 hooks in each fascicle. The hooded hooks of $N$. harrisae have an angled node and three apical rows of teeth; those of $N$. dexterae have a bulbous node and five apical rows of teeth.

\section{Notodasus hartmanae $\mathrm{n} . \mathrm{sp}$.}

Fig. 4A-D, 8D

Type material. Holotype (UANL 6513), 6 Paratypes (UANL 6514), 3 Paratypes (LACM-AHF), 3 Paratypes (MNHN), 3 Paratypes (ZMH), Paredón, Mar Muerto, Chiapas, $16^{\circ} 03^{\prime} 26^{\prime \prime} \mathrm{N}, 93^{\circ} 52^{\prime} 34^{\prime \prime} \mathrm{W}$, $0.5 \mathrm{~m}$ depth, April 14 2008, coll. JALG.

Description. Holotype anterior fragment with 44 segments, $34 \mathrm{~mm}$ long, $4 \mathrm{~mm}$ wide in abdomen. Paratypes and other specimens $15-35 \mathrm{~mm}$ by 2-4 mm. Colour in alcohol dark brown. Prostomium rounded with palpode. Eyespots present, partially covered by anterior margin of peristomium. Thorax, first two abdominal segments and prechaetal area of the third one with tessellated epithelium dorsally (Fig. 4A, B).

Thorax with 11 biannulate chaetigers, with bilimbate capillaries in both rami. Notopodia lateral in anterior thoracic segments, moving dorsally in subsequent segments. Lateral organs present between 


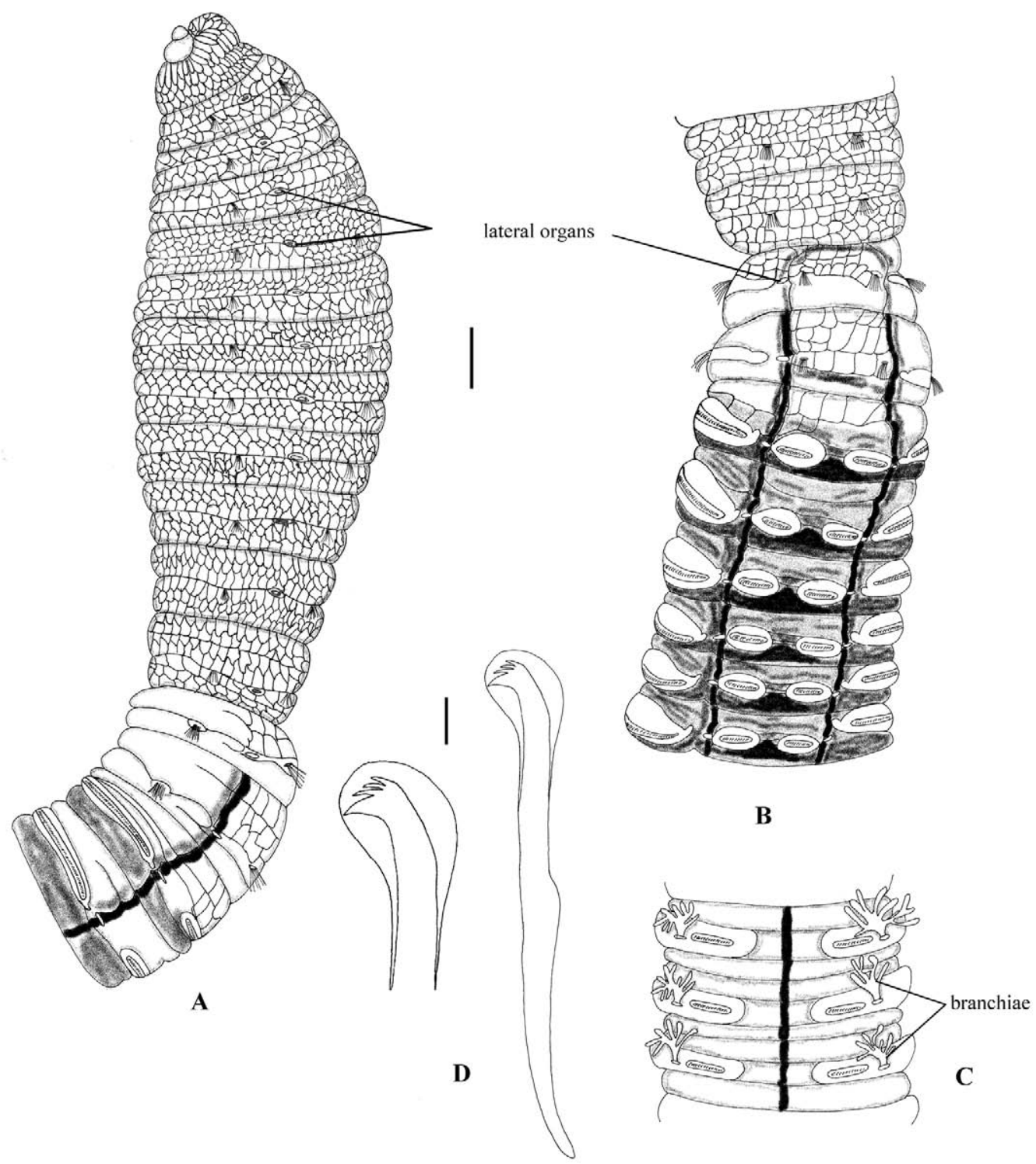

Fig. 4. - Notodasus hartmanae n. sp. A, anterior end, lateral view; B, chaetigers 10-19, dorsal view; C, chaetigers 60-62, ventral view; D, notopodial hook from chaetiger 14, lateral view, and detail. Shading on A-C indicates methyl green stain. Scale bar: AC $=1 \mathrm{~mm}, \mathrm{D}=15 \mu \mathrm{m}$.

notopodia and neuropodia; those of abdominal region closer to neuropodia, larger than thoracic organs. Genital pores absent.

Transition between thorax and abdomen marked by an abrupt increase in the height of each segment; the first two abdominal segments triannulate with bilimbate capillaries in both rami; subsequent abdominal segments shorter, triannulate with only hooded hooks.

Each abdominal segment longer than thoracic ones. Notopodial lobes free along all abdominal segments, each notopodium with around 80 hooded hooks (Fig. 4B). Neuropodial lobes extending from ventrum part to latero-dorsal position, with fascicles of around 200 hooks. Notopodial and neuropodial abdominal hooded hooks similar along body, with long anterior shaft, angled node, distinct constriction, developed shoulder, long hood, and posterior shaft longer than anterior one. Three rows of teeth above triangular main fang, basal row with six teeth, middle row with seven, distal row with three. (Fig. 4D).

Branchiae emerge from a ventral pore, evident from chaetiger 59, with around 15-20 well developed filaments (Fig. 4C). Pygidium not seen. Posterior part of body with eggs in coelom, each egg $22.7 \mu \mathrm{m}$ in diameter.

Methyl green staining pattern. Thoracic region weakly staining, dorsum of abdominal region slight- 
ly darkly staining except at the notopodial and neuropodial lobes, moderately staining longitudinal line with two lateral dark lines between notopodia and neuropodia (Figs. 4B, 8D). Abdomen with a dark, thin mid-ventral line (Fig. 4C).

Remarks. N. hartmanae n. sp. and N. salazari $\mathrm{n}$. sp. are similar in that, unlike other species in this genus, they have free abdominal notopodial lobes. These two species differ in epithelium rugosity; in $N$. salazari, the epithelium is tessellated up to chaetiger 7 , becoming smooth posteriorly, while $N$. hartmanae is tessellated along the entire thorax and the first three abdominal chaetigers, becoming posteriorly smooth.

Habitat. Compact mud, among numerous tubes of Diopatra rhizophorae Grube, with high content of organic matter.

Type locality. Paredón, Mar Muerto, Chiapas (Pacific coast of Mexico).

\section{Distribution. Chiapas, Mexico.}

Ethymology. This species is named to honour the late Dr. Olga Hartman, in recognition of her many useful publications on polychaetes, especially for her study on capitellids and her contributions to the study of polychaetes from western Mexico.

\section{Notodasus kristiani $\mathrm{n}$. sp.} Fig. 5A-D, 8E

Type material. Holotype (UANL 6515), 20 Paratypes (UANL 6517), 2 Paratypes (LACM-AHF), 1 Paratype (MNNH), 1 Paratype (ZMH), Varadero beach, Guaymas, Sonora, 27 $54^{\prime} 04.3^{\prime \prime} \mathrm{N}, 110^{\circ} 52^{\prime} 07.7^{\prime \prime} \mathrm{W}$, 1 m depth, July 01 2005, coll. MEGG and JALG.

Non-type material. Two specimens (ECOSUR), Municipal beach, Los Angeles bay, Baja California, 28 $56^{\prime} 32.3^{\prime \prime} \mathrm{N}, 113^{\circ} 33^{\prime} 57.2^{\prime \prime} \mathrm{W} 1$ m depth, May 24 1986, coll. P. Sánchez and E. Espinosa. One specimen (UANL 6515), Estero Rancho Nuevo, Santa Marina bay, Baja California Sur, $24^{\circ} 19^{\prime} 15^{\prime}$ 'N, $111^{\circ} 25^{\prime} 05^{\prime}$ 'W, 3 m depth, June 21 1998, coll. JALG.

Description. Holotype incomplete with $59 \mathrm{seg}$ ments, $30 \mathrm{~mm}$ long, $3 \mathrm{~mm}$ wide in abdomen. Paratypes and other specimens 25-85 mm long, 2-4 mm wide. Colour in alcohol light brown. Prostomium conical with palpode. Eyespots present, covered by anterior margin of peristomium. Peristomium to the eighth thoracic chaetiger tessellated, remaining segments smooth (Fig. 5A).
Thorax with 11 chaetigers, with bilimbate capillaries in both rami. Thoracic and abdominal segments biannulated. Notopodia lateral in the first thoracic segments, moving dorsally in subsequent segments. Lateral organs, between notopodia and neuropodia throughout body, those of thoracic region closer to notopodium, those in the abdominal closer to neuropodial lobe; thoracic lateral organs larger than abdominal ones. Genital pores between segments 9-10.

Transition between thorax and abdomen marked by abrupt shortening of abdominal segments. Notopodial lobes of abdominal chaetigers 3-7 fused dorsally (Fig. 5B), each line of hooded hooks completely separated, with around 20 hooks per fascicle. Neuropodial lobes separate ventrally, with chaetal fascicles with about 80 hooded hooks (Fig. 4C). Notopodial and neuropodial abdominal hooded hooks similar along the body, with long anterior shaft, bulbous node, indistinct constriction, developed shoulder, short hood, posterior shaft longer than anterior one. Four rows of teeth above triangular main fang, basal row with five teeth, middle basal row with seven, middle apical row with nine and distal row with two teeth. (Fig. 5D).

Branchiae emerge from a ventral pore, evident from chaetiger 51, with around 18 well-developed filaments (Fig. 5C). Pygidium not seen. Posterior part of body with eggs in coelom, each egg 113.5 $\mu \mathrm{m}$ in diameter.

Methyl green staining pattern. Peristomium and first five chaetigers weakly staining, chaetiger 6 to the second abdominal more darkly staining. Third to sixth abdominal chaetiger with two dorsal transverse, darkly staining bands, separated by notopodia and lateral organs (Figs. 5B, 8E); remaining abdominal segments moderately staining.

Habitat. Mud with high content of organic matter (Varadero beach), in soft sediments retained into Nastier boxes (Santa Marina bay), and mud pockets between Mytilus edulis beds (Los Angeles Bay, Municipal beach).

Type locality. Varadero Beach, Guaymas Bay (Gulf of California).

Distribution. Gulf of California and western coast of Baja California. 


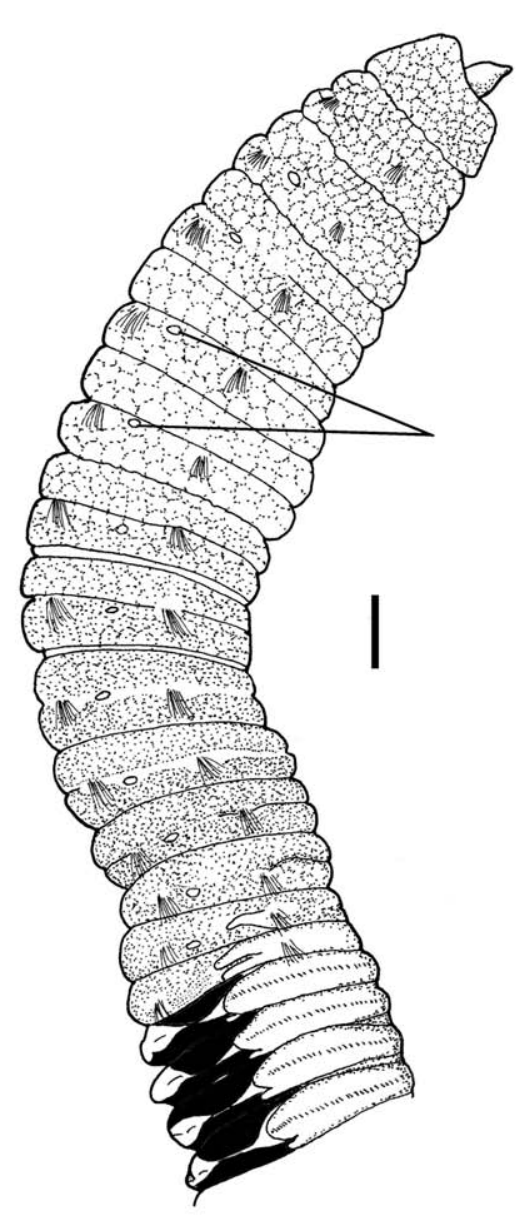

A

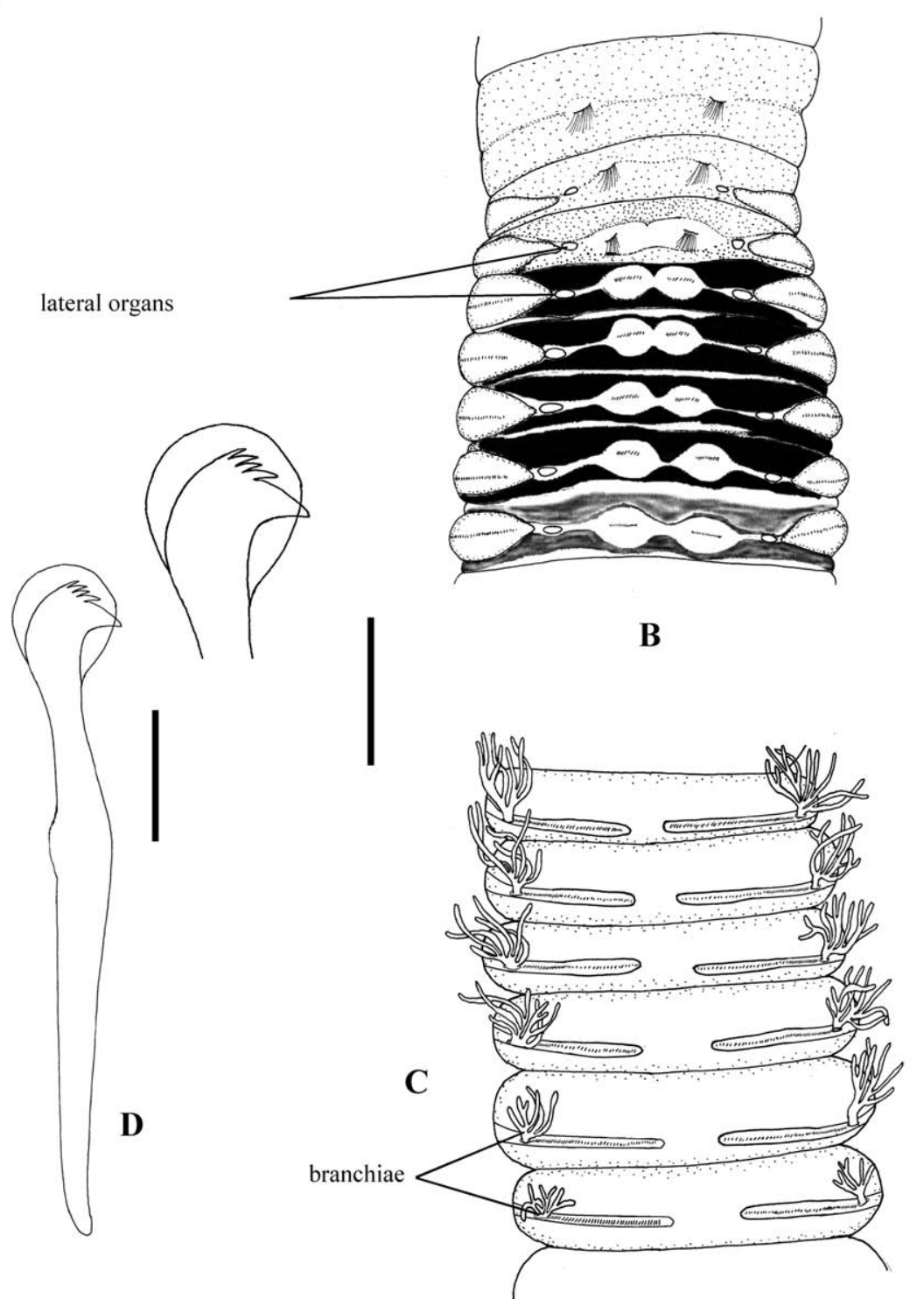

FIG. 5. - Notodasus kristiani n. sp. A, anterior end, lateral; B, chaetigers 11-18, dorsal view; C, chaetigers 18-23, ventral view; D, neuropodial hook from chaetiger 30, lateral view, and detail. Shading on A-B indicates methyl green stain. Scale bar: A-C $=1 \mathrm{~mm}, \mathrm{D}=15 \mu \mathrm{m}$.

Etymology. The species is named in honour of Kristian Fauchald, who established Notodasus and described two of its species, and especially in recognition of his many contributions to the study of polychaetes.

Remarks. N. kristiani n. sp. resembles $N$. arenicola in having a constriction of notopodial fused lobes in the entire abdominal parapodia. They differ in the shape of the neuropodial lobes, which are free along the entire body in N. kristiani and fused in N. arenicola, expanded on the anterior region, and considerably reduced posteriorly. Further, their MGSP is very different, as described above.
Notodasus magnus Fauchald, 1972 Fig. 6A-D, 8F

Notodasus magnus Fauchald, 1972: 246-247, pl. 51 fig. a-c.

Material examined. Holotype (LACM-AHF POLY-031), SW Punta Arena, Carmen Island, Gulf of California, from $25^{\circ} 46^{\prime} 00^{\prime} \mathrm{N}$, $111^{\circ} 15^{\prime} 00^{\prime \prime} \mathrm{W}$, to $25^{\circ} 49^{\prime} 40^{\prime \prime N}, 111^{\circ} 15^{\prime} 30^{\prime \prime} \mathrm{W}, 29-35 \mathrm{~m}$ depth, March 181949.

Redescription. Holotype an anterior fragment, with 92 chaetigers, $90 \mathrm{~mm}$ long, $5 \mathrm{~mm}$ wide in the abdomen. Colour in alcohol light brown. The epithelium slightly damaged. Prostomium is conical with palpode. Eyespots absent. Peristomium tessellated, thoracic epithelium longitudinally striated, abdomi- 

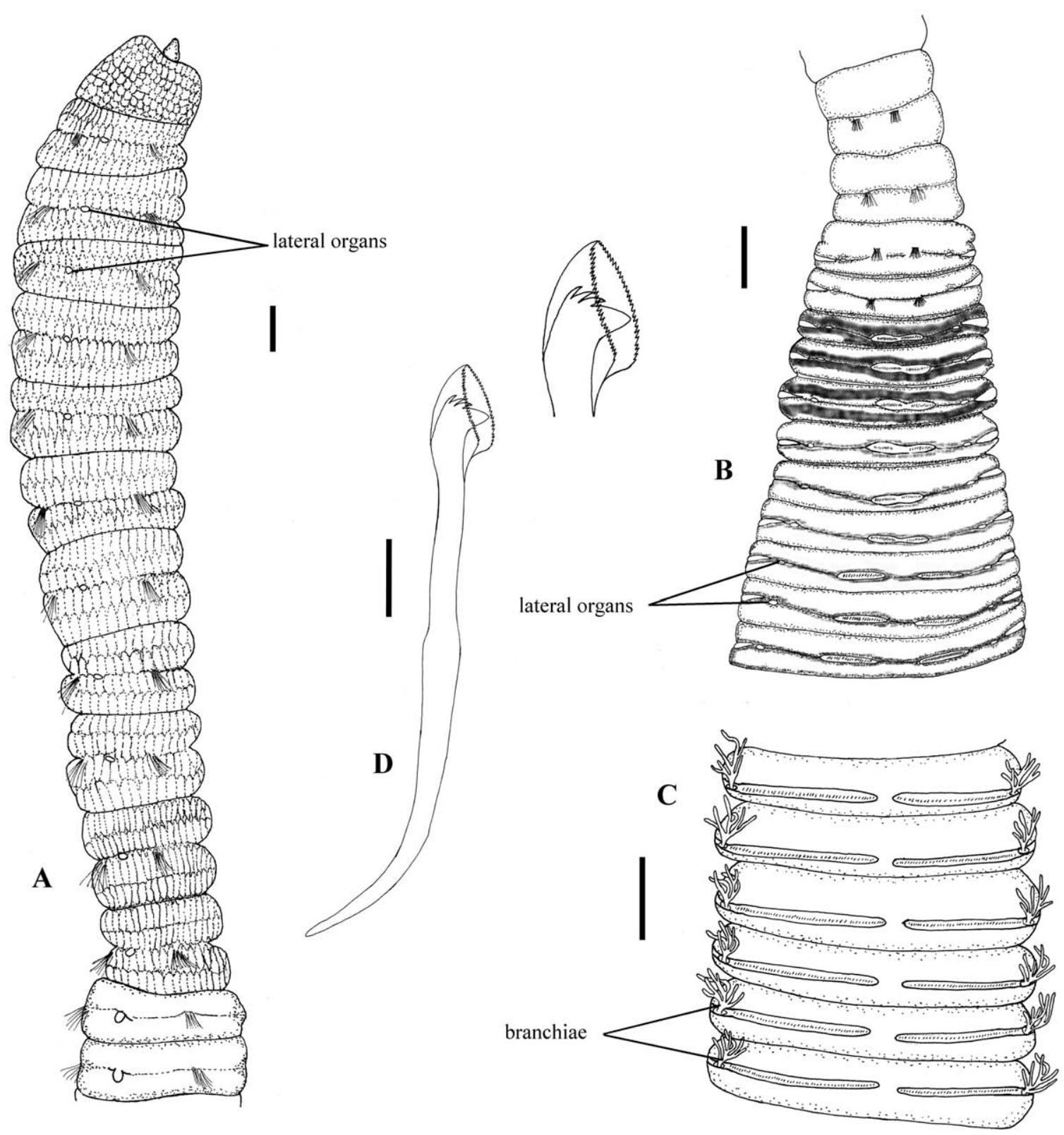

FIG. 6. - Notodasus magnus: A, anterior end, lateral view; B, chaetigers 10-22, dorsal view; C, chaetigers 50-55, ventral view; D, neuropodial hook from chaetiger 28 , lateral view, and detail. Shading on A-B indicates methyl green stain. Scale bar: A-C = $1 \mathrm{~mm}, \mathrm{D}=10 \mu \mathrm{m}$.

nal segments with smooth epithelium (Fig. 6A).

Thorax with 11 chaetigers, with bilimbate capillaries in both rami. Thoracic segments biannulate, anterior abdominal segments also biannulate, triannulate posteriorly. Notopodia lateral in the first thoracic segments, moving dorsally in subsequent segments.

Lateral organs located between notopodia and neuropodia; those of thoracic region closer to notopodium, rounded like pores, those of the abdomen as small protuberances found closer to neuropodial lobe. Genital pores not seen.
Transition between thorax and abdomen marked by sharp reduction in last thoracic segment length. Notopodial lobes of abdominal chaetigers 3-8 fused dorsally, those of subsequent chaetigers separate (Fig. 6B); notopodial fascicles with a line of around 40 hooded hooks. Neuropodial lobes separate ventrally, extending to dorso-lateral region, with a line of around 90 hooded hooks per fascicle ventrally on the neuropodium, (Fig. 6C). Notopodial and neuropodial abdominal hooded hooks similar along body, with long anterior shaft, well developed node, distinct constriction, wide shoulder, well developed 
hood, posterior shaft longer than anterior one, slightly curved. Three rows of teeth above triangular main fang, basal row with six teeth, middle row with five and distal row with three small denticles. (Fig. 6D).

Branchiae emerging from a ventrolateral pore of neuropodial lobe, distinct from chaetiger 61, with around six filaments per branchiae (Fig. 6C). Pygidium not seen. Posterior part of body with eggs in coelom, each egg $6.8 \mu \mathrm{m}$ in diameter

Methyl green staining pattern. Weakly staining dorsally from thorax to second abdominal segment, third to fifth abdominal chaetiger with a darker prechaetal and postchaetal transverse band, remaining chaetigers unstained (Figs. 6B, 8F).

Habitat. This species is known from one locality, collected by dredge in sediments with sand, mud and pebbles, 29-35 m depth.

Type locality. SW Punta Arena, Carmen Island (Gulf of California).

\section{Distribution. Gulf of California.}

Remarks. One of the characters that Fauchald (1972) employed to differentiate Notodasus from other genera was the absence of notopodial setae on the first thoracic chaetiger; however, we have observed that the first chaetiger is biramous in the holotype of $N$. magnus. Fauchald also failed to note the presence of branchiae on the posterior region, and lateral organs in the entire length of the body.

\section{Notodasus salazari n. sp.}

Fig. 7A-D, 8G

Type material. Holotype (UANL 6518), 1 paratype (LACM-AHF), Contoy Island National Park, Quintana Roo, 21 ${ }^{\circ} 27^{\prime} 37.86$ 'N, $86^{\circ} 47^{\prime} 8.94$ 'W, $0.70-0.90 \mathrm{~m}$ depth, February 21 2008, coll. MEGG and S. I. Salazar-Vallejo.

Description. Holotype complete, about 400 segments, $185 \mathrm{~mm}$ long, $2.7 \mathrm{~mm}$ wide in abdomen. Paratype incomplete with 30 segments, $25 \mathrm{~mm}$ long, $2.5 \mathrm{~mm}$ wide. Colour in alcohol light brown. Prostomium conical with palpode. Eyespot present, covered by anterior margin of peristomium. Peristomium, first seven thoracic segments, and prechaetal area of chaetiger 8 with a tessellated epithelium; remaining segments smooth (Fig. 7A).

Thorax with 11 chaetigers, with bilimbate capillaries in both rami. Thoracic and first two abdominal segments biannulated, abdominal segments uniannulated. Notopodia lateral on thoracic segments, on abdominal segments dorsal.

Lateral organs present along entire body, between notopodia and neuropodia, those of thoracic region closer to notopodium, closer to neuropodia in abdominal segments. Genital pores present on all abdominal segments.

Transition between thorax and abdomen marked by abrupt decrease in segment length; first two abdominal segments with capillaries in both rami; subsequent abdominal segments with hooded hooks only (Fig. 7B). Notopodial lobes of each abdominal segment separated medially, each one with about 40 hooded hooks. Neuropodial abdominal lobes separated ventrally, extending to lateral surface, chaetal fascicles with about 90 hooded hooks (Fig. 7C). Notopodial and neuropodial abdominal hooded hooks similar along body, with long anterior shaft, angled node, evident constriction, developed shoulder, short hood, and posterior shaft longer than anterior one but attenuate to terminal end. Main fang subtriangular, longer than wide: three rows of teeth above main fang, basal row with five teeth, middle row with six, and distal row multidentate (Fig. 7D).

Branchiae emerge from a ventral pore, evident from chaetiger 72, with about 6-7 well developed filaments (Fig. 7E). Pygidium with a triangular caudal cirri. Posterior part of body with eggs in coelom, each egg $11.3 \mu \mathrm{m}$ in diameter.

Methyl green staining pattern. Peristomium and first two chaetigers with large moderately staining dorsum. First two abdominal segments strongly staining, following abdominal segments with moderately staining transverse postchaetal band (Figs. 7A-B, C, E, 8G).

Remarks. Notodasus salazari n. sp. differs from other species by the abdominal notopodial lobes being separated throughout. The first six abdominal segments of $N$. magnus have fused with notopodial lobes, while those of the remaining segments are separated as in $N$. salazari but the epithelium in $N$. magnus is longitudinally striated in chaetigers 1-11, while in N. salazari the epithelium is tessellated from chaetigers 1 to 7 . The methyl green stain pattern of the first two abdominal segments in $N$. salazari with completely staining is also distinctive, as he other Notodasus species have incomplete staining on the first two abdominal segments. 

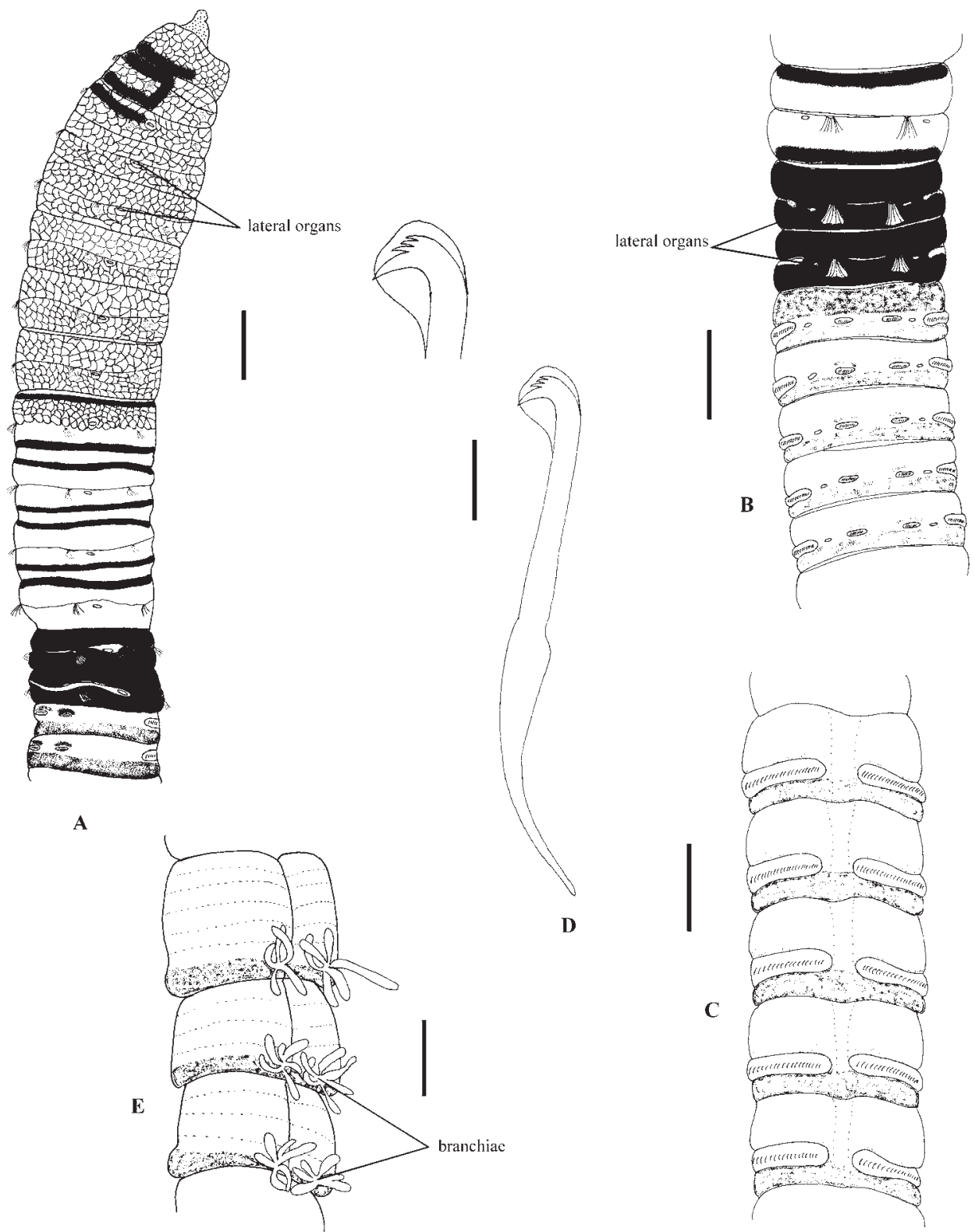

FIG. 7. - Notodasus salazari n. sp. A, anterior end, lateral view; B, chaetigers 11-18, dorsal view; C, chaetigers 31-35, ventral view; D, neuropodial hook from chaetiger 50, lateral view, and detail; E, chaetigers 260-262, lateroventral view. Shading on A-C, E indicates methyl green stain. Scale bar: A-C, E = $1 \mathrm{~mm}, \mathrm{D}=10 \mu \mathrm{m}$.

Hábitat. Fine sand associated with Talassia testudinum.

Type locality. Contoy Island, Quintana Roo.

Distribution. Mexican Caribbean.

Etymology. This species is named after Sergio I. Salazar-Vallejo in recognition of his efforts to increase the knowledge of polychaetes in Mexico.

\section{Key to species of Notodasus}

1. Thoracic epithelium longitudinally striated; eyes absent N. magnus

- Thoracic epithelium tessellated; eyes present......2

2. Abdominal notopodial lobes fused 3

- Abdominal notopodial lobes with a median constriction 4

- Abdominal notopodial lobes completely free..... 5 

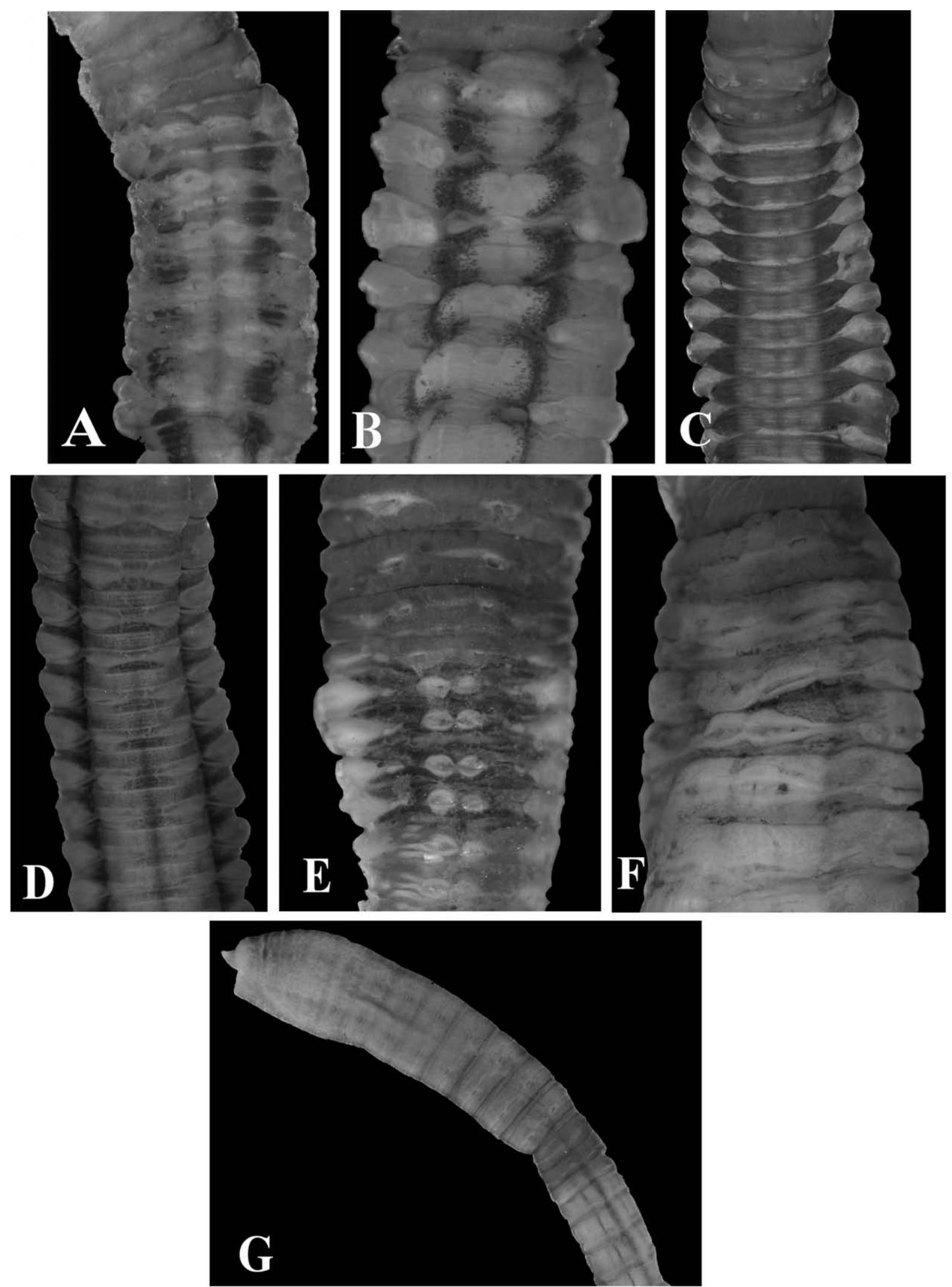

FIG. 8. - Methyl green staining pattern: A, Notodasus arenicola, chaetigers 12-18, dorsal view; B, Notodasus dexterae, chaetigers 11-17, dorsal view; C, Notodasus harrisae n. sp., chaetigers 11-24, dorsal view; D, Notodasus hartmanae n. sp., chaetigers 12-20, dorsal view; E, Notodasus kristiani n. sp., chaetigers 10-18, dorsal view; F, Notodasus magnus, chaetigers 12-17, dorsal view; G, Notodasus salazari n. sp., anterior end, lateral view. 
3. Fascicles of anterior abdominal notopodial hooded hooks forming almost a continuous line; abdominal lateral organs small $N$. harrisae n. sp.

- Fascicles of anterior abdominal notopodial hooded hooks clearly separate; abdominal lateral organs expanded N. dexterae

4. Posterior neuropodial lobes small, fused medially N. arenicola

- Posterior neuropodial lobes longer, expanded to dorsolateral area, separated medially N. kristiani n. sp.

5. All thoracic segments with tessellated epithelium, methyl green stain dark green on first two abdominal chaetigers N. salazari $\mathrm{n} . \mathrm{sp}$.

- Tessellated epithelium only on segments 1-7, methyl green staining with two dark green longitudinal lines along dorsum on abdomen ..... N. hartmanae n. sp.

\section{CONCLUSIONS}

Fauchald (1972) describes Notodasus based on a single specimen collected in the Gulf of California for $N$. magnus. Since then, only two species have been described, $N$. dexterae Fauchald (1973) for the Pacific coast of Panama, and N. arenicola HartmannSchröder (1992) from the mid-Atlantic Ocean. The knowledge of these species had been limited only to the original descriptions. Some bad interpretations or omissions of several characters were found with revision of the type material of each species, which include the form of the first chaetiger, presence of lateral organs, genital pores and branchiae, as well as the notopodial lobes shape and hooded hooks. Based on specimens found on the Mexican coasts, in this work four species of Notodasus were described, evidencing the little knowledge of this group.

\section{ACKNOWLEDGEMENTS}

This study was funded by the Mexican agencies SEMARNAT-CONACYT (Projects 2004-C01-254/A-1 and 61609). We thank Andrea Prado, Francisco Javier Quiñones and Susana Pérez, for their help in collecting and sorting samples in the Gulf of California, and Sergio I. Salazar-Vallejo, Luis Fernando Carrera-Parra and Humberto Bahena-Basave for helping us during field work at Contoy Island and in the southwestern Mexican Pacific; LFC-P provided us with the name of the species Diopatra rizophorae. We are indebted to Leslie Harris (LACM-AHF) and to Angelika Brandt and Jürgen Guerrero Kommritz (ZMH) for help during our visits to their museums. Additional material was kindly provided by Norma Emilia Gonzlález (El Colegio de la Frontera Sur, ECOSUR), Nuria Méndez (Instituto de Ciencias del Mar y Limnología, Unidad Mazatlán), and Alejandra Chávez (Centro Interdisciplinario de Ciencias del Mar, CICIMAR). We thank Mario Londoño Mesa and Sergio I. Salazar-Vallejo, who reviewed a previous draft of this manuscript. Two anonymous referees greatly improved the quality of the paper.

\section{REFERENCES}

Fauchald, K. - 1972. Benthic polychaetous annelids from deep waters off Western Mexico and adjacent areas in: the Eastern Pacific Ocean. Allan Hancock Found., Monogr. Mar. Biol., 7: 1-575.

Fauchald, K. - 1973. Polychaetes from Central American sandy beaches. Bull. South. Calif. Acad. Sci., 72: 19-31.

Green, K.D. - 2002. Capitellidae (Polychaeta) from the Andaman Sea. Phuket Mar. Biol. Cent. Spec. Publ., 24: 249-343.

Hartman, O. - 1947. Polychaetous annelids, 7. Capitellidae. Allan Hancock Pac. Exped. 10(4-5): 391-481

Hartmann-Schröder, G. - 1992. Die Polychaeten der AmsterdamExpedition nach der Insel Ascension (Zentral-Atlantik). Bijdr. Dierk., 61: 219-235.

McCammon, J.A. and J.K. Stull. - 1978. A new genus and species of Capitellidae (Polychaeta) from California. Bull. South. Calif. Acad. Sci., 77(1): 40-43.

Méndez, N. - 2002. Preliminary observations on the effect of cadmium on larval development of Capitella sp. B from Barcelona. Bull. Mar. Sci. 70:899-908

Reish, D.J. - 1957. The relationship of the polychaetous annelid Capitella capitata (Fabricius) to waste discharge of biological origin. In: C.M. Tarzwell (ed.) Biological Problems in Water Pollution, pp. 195-200. U.S. Public Health Service, Washington.

Warren, L.M., P.A. Hutchings and S. Doyle. - 1994. A revision of the genus Mediomastus Hartman, 1944 (Polychaeta: Capitellidae). Rec. Austr. Mus., 46: 227-256.

Scient. ed.: D. Martin

Received July 24, 2008. Accepted January 30, 2009.

Published online October 6, 2009. 